\title{
TRANSFORMERLESS STEP-UP INVERTER BASED ON SWITCHED-CAPACITOR CONVERTER TECHNOLOGY
}

\author{
Neilor Colombo Dal Pont ${ }^{1}$, Gierri Waltrich ${ }^{2}$, Telles B. Lazzarin ${ }^{1}$ \\ ${ }^{1}$ Federal University of Santa Catarina, Department of Electrical Engineering, Florianópolis-SC, Brazil \\ ${ }^{2}$ Federal University of Santa Catarina, Department of Mobility Engineering, Joinville-SC, Brazil \\ e-mail: neilorcolombodalpont@gmail.com, gierri@gmail.com, tellesbl@gmail.com
}

\begin{abstract}
In this paper the integration between a voltage source inverter (VSI) and a switched capacitor converter (SCC) is proposed to generate a sinusoidal waveform with a double peak voltage value at the converter output terminal, without the use of a transformer or a dc-dc boost converter. The novel structure (VSI-SCC) is designed as a transformerless step-up inverter with linear gain. VSI and SCC models are individually characterized to integrate both structures in only one model. To validate the theoretical analysis a prototype was designed for a power of $1 \mathrm{~kW}$, considering a dc input voltage of $200 \mathrm{~V}$ and an ac output voltage of $220 \mathrm{~V}$ (rms). In this prototype the VSI converter supplies $110 \mathrm{~V}$ (rms) to the SCC converter, and this converter step-up it to $220 \mathrm{~V}$ (rms). Furthermore, open and closed-loop control were also tested in the prototype reaching a maximum efficiency of $90 \%$.
\end{abstract}

Keywords - Linear Gain, Step-up Inverter, SwitchedCapacitor, Transformerless.

\section{INTRODUCTION}

In recent years voltage source inverters (VSIs) have been used in a wide range of applications associated with, for instance, renewable energy sources, distributed generation systems, uninterruptible power supply (UPS), electric and hybrid vehicles and smart-grids [1]-[4]. In the majority of cases VSI topologies are employed as step-down inverters (half-bridge, full-bridge, etc.), mainly due to their simple control system and linear gain characteristics.

On the other hand, step-up inverters [5]-[12] present nonlinear gain characteristic, such as Z-source [8]-[11] and SEPIC [12] inverters. These structures increase the control system complexity and make it difficult to obtain a sinusoidal waveform at the converter output. Other way to obtain a stepup structure is using a two-stage boost-buck inverter, which employs a dc-dc converter to increase the dc voltage and a conventional inverter to supply the ac voltage. This solution introduces higher voltage stress on the semiconductors.

The simplest solution to boost the VSI output voltage is the use of a low-frequency transformer, which is the technique most commonly employed in industry, due to its simplicity and robustness. However, low-frequency transformers require large cores, resulting in heavy and bulky magnetic components.

Manuscript received 24/10/2016; first revision 25/11/2016; accepted for publication 16/01/2017, by recommendation of Editor Marcelo Cabral Cavalcanti
Recently, switched-capacitor dc-dc converters have been used to multiply or divide voltage. The integration between switched-capacitor (SC) principles and traditional converters has been a good option to increase the rated conversion of conventional structures, as verified in [13]-[16] for dc-dc converter, [17] for rectifier and [18] for inverters. Some disadvantages of SC circuits, as parasitic elements, hard switching and peak of current, limited their power. However, recent research has been developed, as in [19]-[22], to increase the power range of SC application.

In this context, in this paper, the integration between a VSI and a switched-capacitor converter (SCC) topology is proposed, in order to obtain a step-up voltage source inverter with linear gain characteristics without using low-frequency transformers or dc-dc boost stages. The novel structure is named as VSI-SCC.

\section{PROPOSED INTEGRATION BETWEEN INVERTER AND SWITCHED-CAPACITOR}

The proposed converter is shown in Figure 1(a). VSI-SCC topology can work in buck or boost mode and it allows a bidirectional power flow. Furthermore, the proposed converter also presents split-phase characteristics at the output stage (voltages under $C_{2}$ and $C_{3}$ ), which can expand the range of potential applications for the proposed converter. The main aim behind this topology is to boost the VSI output voltage using an ac-ac SCC [23], [24] topology instead of a transformer. The only magnetic device of the proposed topology is the inductor on the filter stage. The capacitor $C_{1}$, at the filter stage, is the integrating element, being part of both converters (VSI and SCC). In [18] are shown preliminary results of the proposed structure. This study presents more complete experimental results, besides a $n$ cells SCC analysis and a comparison between this structure and other boost inverters. In [25] is shown a VSI+SCC step down structure and in [26] and [27] a dc-dc SCC is employed at the VSI input.

\section{A. Voltage Source Inverter}

The inverter implemented in the proposed converter is a full-bridge inverter with an output filter and a three-level PWM modulation. The peak voltage value of this converter is defined by:

$$
V_{i p}=M E
$$

where:

$M \quad$ - Index modulation;

$E \quad$ - Input voltage. 


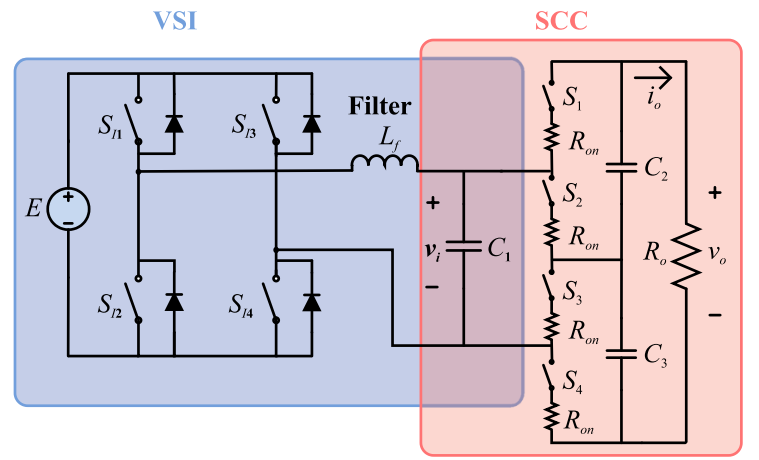

(a)

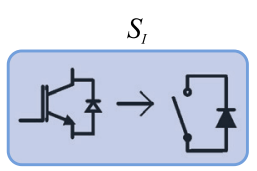

(b)

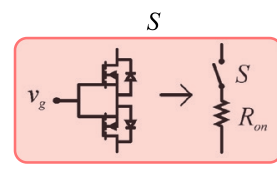

(c)
Fig. 1. Proposed topology and switch models: (a) Proposed topology; (b) VSI switch model; (c) SCC four-quadrant switch model.

\section{B. Passive Filter (LC)}

A conventional second-order passive filter LC is employed between the VSI and the SCC. The inductor $L_{f}$ in Figure 1(a) is designed considering the current ripple in accordance with:

$$
\Delta_{I_{L}}=\frac{E V_{i p} \sin (\omega t)}{2 E L_{f} f_{s}}
$$

where $f_{s}$ is the switching frequency.

The filter capacitor is defined by the SCC equivalent capacitance and will be described in a later section.

\section{Switched-Capacitor Converter}

The SCC shown on the right side of Figure 1(a) is a stepup ac-ac converter. This converter naturally equalizes the capacitor voltages of $C_{2}$ and $C_{3}$ if these capacitances and switching frequencies are properly designed, as demonstrated in [23]. The resistance, $R_{o n}$, in Figure 1(a) represents the equivalent series resistance of the four-quadrant switch, obtained from the manufacturer datasheet.

The SCC topology can operate in buck or boost mode and, since a higher output voltage is desired in this study, the boost mode was used. For the boost mode there are two different operational stages. The first is when the switches $S_{1}$ and $S_{3}$ are turned on, as shown in Figure 2(a). In this operational stage the $C_{1}$ voltage is equalized with the $C_{2}$ voltage. In the second stage, shown in Figure 2(b), the switches $S_{1}$ and $S_{3}$ are blocked and $S_{2}$ and $S_{4}$ are turned on and therefore the $C_{1}$ voltage is equalized with the $C_{3}$ voltage. The gate signals of the SCC are shown in Figure 2(c). Usually, a dead-time is imposed in the switching between the $S_{1}-S_{3}$ and $S_{2}-S_{4}$ to avoid a short circuit.

The duty cycle must be close to 0.5 to equalize both the $C_{2}$ and $C_{3}$ voltage values with the lowest impedance. Thus, it is assumed that this topology has a fixed duty cycle and it works in open-loop.

The presented analysis in this section was carried out considering the positive semi-cycle of the sinusoidal waveform, however, for the negative part it works in a dual way. In Figure 3 the voltage and the current waveforms for the capacitors and the switches of the SCC topology for both positive and negative sinusoidal semi-cycle parts are shown. The attributed current flow for Figure 3 is shown in Figure 2(a) and 2(b).

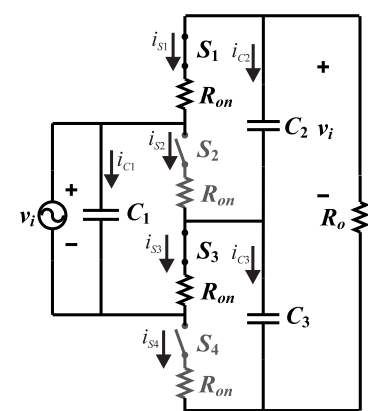

(a)

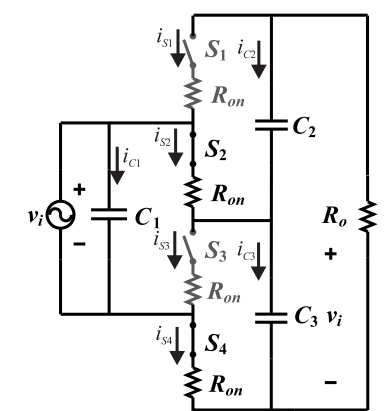

(b)

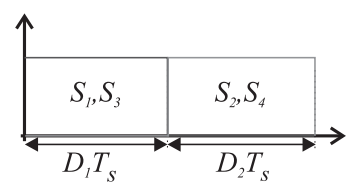

(c)

Fig. 2. Operational stages of the SCC topology: (a) First operational stage; (b) Second operational stage; (c) SCC gate signals.
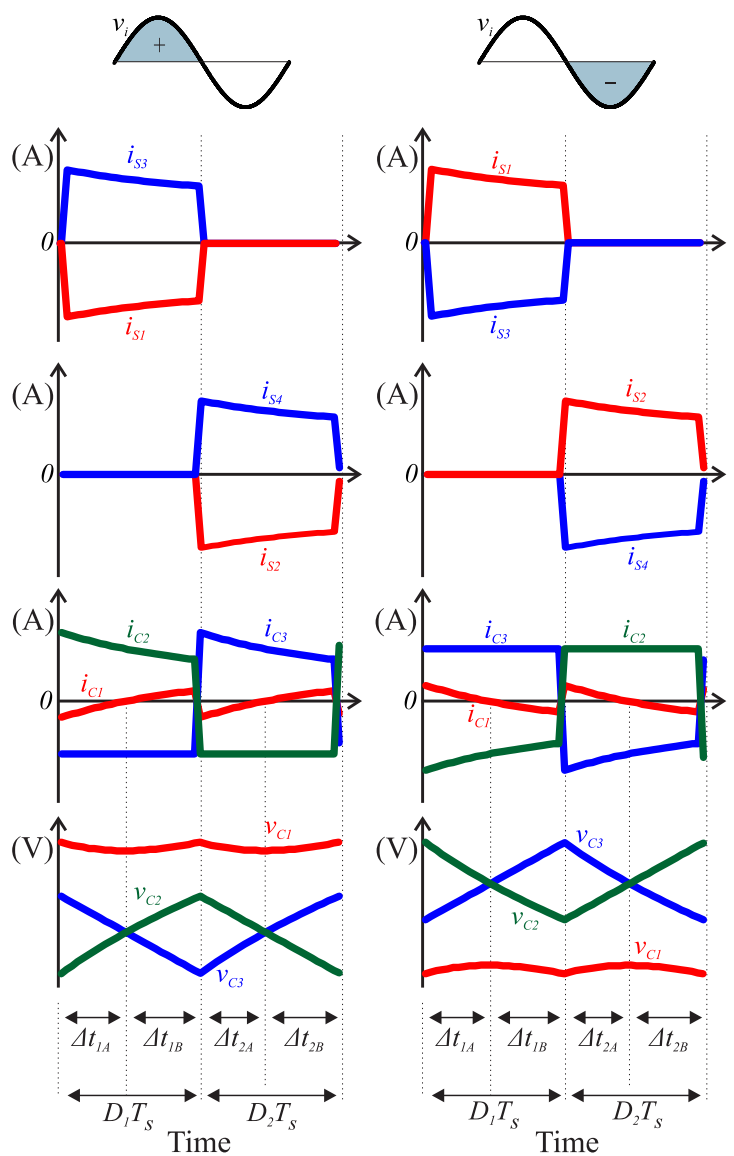

Fig. 3. Voltage and current waveforms for the switches and the capacitors of the SCC topology considering positive and negative sinusoidal semi-cycles. 
In accordance with [28] and [29], SCC topologies can operate in three different ways, based on the capacitor current $\left(i_{c}\right)$. That ways depending on the switched capacitor, $R_{o n}$ and the operating frequency. These operational modes are the complete charge (CC), the partial charge (PC) and the no charge (NC) mode. The waveforms for the operational charging modes are shown in Figure 4 . In the $\mathrm{CC}$ mode the current on the switched capacitor $C_{1}$ reaches zero, but the currents in modes PC and NC do not. Also, in the CC mode the current reaches high values and, consequently, higher losses occur. Therefore, this mode is not a good choice for the converter proposed in this paper. On the other hand, the $\mathrm{NC}$ mode requires high capacitance and switching frequency values, leading to high costs and technological limitations. Thus, the mode which provides the best results is the PC mode and for this reason it was used in this study.

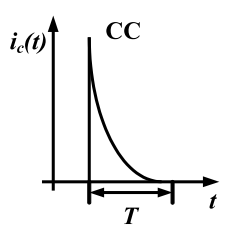

(a)

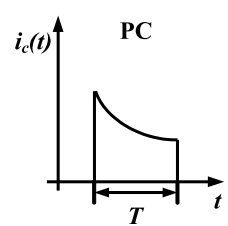

(b)

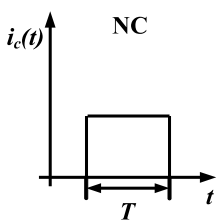

(c)
Fig. 4. SSC operational charging modes: (a) Complete charge (CC); (b) Partial charge (PC); (c) No charge (NC).

Considering a low frequency analysis, $v_{o}$ in Figure 1(a) can be obtained by summing the voltage across the capacitors $C_{2}$ and $C_{3}$, as described by:

$$
v_{o}=v_{C_{2}}+v_{C_{3}}=v_{i}+v_{i}=2 v_{i}
$$

where:

$v_{i} \quad$ - VSI output voltage;

$v_{o} \quad$ - SCC output voltage.

Thus, from (3) it is possible to determine the static gain, which is the ratio between the output and input voltages given by:

$$
G=\frac{v_{o}}{v_{i}}=\frac{2 v_{i}}{v_{i}}=2 .
$$

As previously described, the gain for the structure proposed in Figure 1(a) is two. However, a higher gain can be obtained if more cells are added in series, as demonstrated in [23] and [28].

The equivalent circuit seen by the low voltage side is shown in Figure 5(a). In this figure it was considered that:

$$
C_{2}=C_{3}=C_{x} .
$$

The duty cycle was equal to 0.5 to balance the capacitor voltages. $R_{e q}$ is the equivalent resistance seen from the low voltage side. The conduction losses of the switched capacitor cell can be designed by a resistance, as discussed in [23], [28] and [29]. This resistance is called of series resistance $\left(R_{S}\right)$, and is given by:

$$
R_{s}=\frac{2 R_{o n}}{f_{s} \tau} \frac{\left(1-e^{-1 / f_{s} \tau}\right)}{\left(1-2 e^{-D / f_{s} \tau}+e^{-1 / f_{s} \tau}\right)} .
$$

The constant time, $\tau$, is obtained by:

$$
\tau=2 R_{o n} C_{1} .
$$

As seen in (6), the value of $R_{s}$ changes for different switching frequencies and $\tau$ values. Thus, in order to understand the behavior of $R_{S},(6)$ was plotted in Figure 5(b) for different $f_{s}$ and $\tau$ values. From this figure it is possible to conclude that, for lower frequencies and $\tau$ values, the series resistance has a higher value and, consequently, the conduction losses are higher. The minimum value for $R_{s}$ is equal to $2 R_{o n}$, in the NC operational mode.

From Figure 5(b) it is also possible to determine the limits for the operational modes [28]. Thus, in order to design a converter to operate in the PC mode, the designer should respect the limits shown in Figure 5(b) [23]. The first limit is given by:

$$
5 \tau>T_{s} / 2 .
$$

Therefore substituting (7) into (8) the following relation is obtained:

$$
2 R_{\text {on }} f_{S} C_{1}>0.1
$$

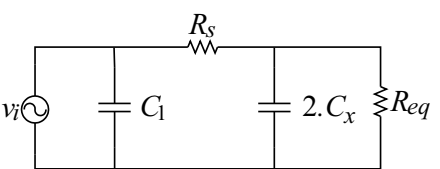

(a)

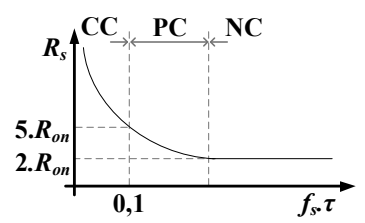

(b)
Fig. 5. SCC parameters: (a) Equivalent circuit; (b) Series resistance $\left(R_{S}\right)$ for different frequency and constant time $\tau$ values.

\section{Integration Seen from the VSI Side}

From the VSI side the SCC topology is seen as an equivalent capacitor, which is part of the passive output filter. This equivalent capacitor can be found disregarding the $R_{o n}$ resistors in Figure 5(a).

Considering the parameters shown in (5) the equivalent capacitance seen from the low voltage side is given by

$$
C_{e q}=C_{1} / / \frac{4 C_{x}}{2}=C_{1} / / 2 C_{x}
$$

\section{E. Integration Seen from the SCC Side}

From the SCC side the VSI is represented by an alternating voltage source added to a high-frequency component generated by the PWM modulation. This high-frequency component will circulate through the SCC components, causing losses. Figure 6 shows the circuit seen from the SCC side for the two operational stages.

\section{F. Static Gain}

The static gain for the complete circuit, i.e., after the integration between VSI and SCC, is obtained multiplying the index modulation $(M)$ by the static gain provided by (4). Thus, the static gain for the proposed converter is: 


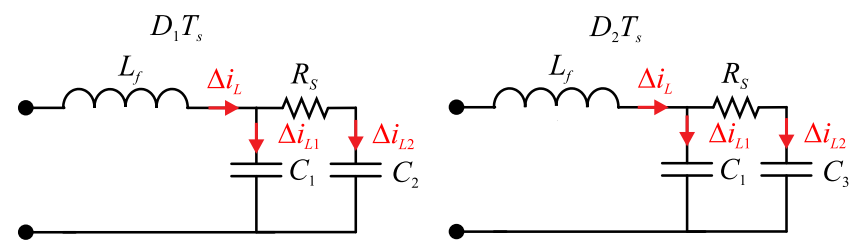

Fig. 6. Circuit seen from the SCC side for the two operational stages.

$$
G_{t}=2 M .
$$

Therefore, the peak voltage value of the proposed converter output voltage is given by:

$$
V_{o p}=2 M E \text {. }
$$

\section{G. Dynamic Analysis in Open-Loop}

Numerical simulations were carried out with open-loop to validate the equivalent capacitance mentioned in subsection D. In the simulation two circuits were observed, one considering the circuit from Figure 1(a) and the other considering $C_{e q}$ obtained in subsection D. The results obtained from the simulation for these two circuits are reported in Figure 7. Based on the similarities in the step responses for the two circuits, it is verified that the equivalent capacitance properly represents the equivalent circuit and can be used in the following analyses.

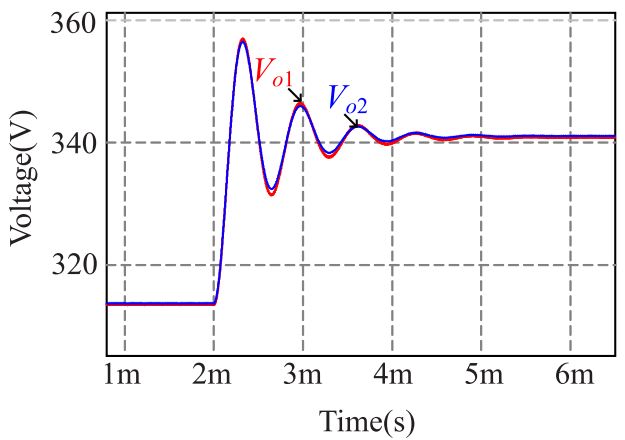

Fig. 7. Step response for comparison between the circuits shown in Figure 1(a) $\left(V_{o 1}\right)$ and using $C_{e q}\left(V_{o 2}\right)$.

\section{H. Dynamic Analysis in Closed-Loop}

The closed-loop control implemented for the output voltage is shown in Figure 8. The feedback control in this topology can be carried out in two different parts of the circuit, i.e., in the VSI output or in the SCC output port. In both cases, the converter model is found with the small-signal model, based on [30], [31], wherein the control variable is the duty cycle. If the feedback control is carried out at the VSI output, the converter model $G_{1}(s)$ in Figure 8 is given by:

$$
G_{1}(s)=\frac{\hat{v}_{i}}{\hat{d}}=\frac{E}{s^{2} L_{f} C_{e q}+s \frac{L_{f}}{R_{e q}}+1} .
$$

On the other hand, if the feedback control is carried out at the SCC output, the converter model is given by:

$$
G_{2}(s)=\frac{\hat{v}_{o}}{\hat{d}}=\frac{2 E}{s^{2} L_{f} C_{e q}+s \frac{L_{f}}{R_{e q}}+1} .
$$

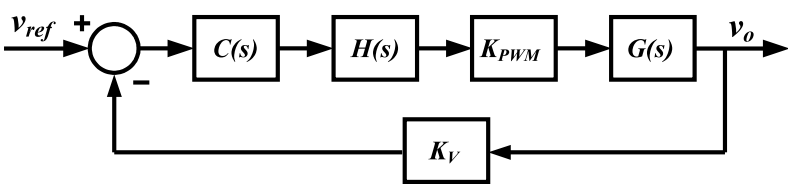

Fig. 8. Closed-loop control diagram.

The frequency response of the open-loop transfer function of the proposed converter $\left(K_{P W M} \cdot K_{v} \cdot G_{1}(s)\right)$ in the no-load case is plotted in the Bode diagram shown in Figure 9. The curve in this figure has multiple zero crossings (around $0 \mathrm{~dB}$ ), which might hinder the converter control. Therefore, to avoid multiple zero crossings, a band-rejection filter was designed and tuned to around the LC filter resonant frequency. The band-rejection filter transfer function is represented by $H(s)$ in Figure 8 and is given by:

$$
H(s)=\frac{s^{2}+\left(2 \pi f_{f}\right)^{2}}{s^{2}+2 \pi f_{a}+\left(2 \pi f_{f}\right)^{2}} .
$$

where:

$f_{f} \quad$ - Center frequency of the band-rejection filter;

$f_{a} \quad$ - Bandwidth of the band-rejection filter.

The controller transfer function is represented by $C(s)$ in Figure 8. To control the proposed converter a PI controller was implemented.

In Figure 8 , the symbols $K_{v}$ and $K_{P W M}$ represent the gain given by the voltage sensor and PWM modulation, respectively.

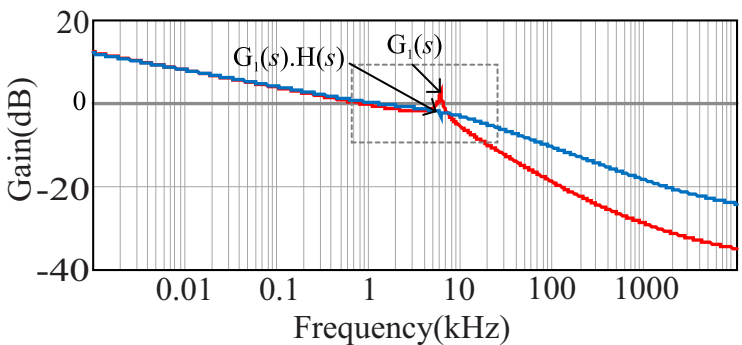

Fig. 9. Frequency response of the open-loop transfer function for the no-load case without and with the band-rejection filter.

\section{GENERALIZATION TO $n$ CELLS}

Up to this point, the analysis was carried out with only one SC cell, composed of two bidirectional switches and two capacitors. If desired, the gain can be increased by cascading more SC cells, as shown in Figure 10. Thus, it is possible to increase the VSI gain by integrating an SCC with $n$ SC cells at the VSI output, as can be seen in Figure 10(d).

The static gain for an $n$-cells SCC is defined by:

$$
G_{n}=n+1
$$

The number of bidirectional switches for $n$ SCC cells is described by:

$$
N_{\text {bid_sw }}=2(n+1) \text {. }
$$

The total number of capacitors for the SCC topology is given by: 


$$
N_{\text {cap }}=n+1 \text {. }
$$

A structure with $n$ SCC cells considering all of the capacitors with the same capacitance values is shown in Figure 10(c). If even and the odd switches of the SCC cells are synchronized, i.e., they commutate at the same time, the voltage balance in all capacitors is guaranteed.

The equivalent capacitance seen by the low voltage side can be found in a way similar to that described in section II-D. Therefore, the equivalent capacitance is given by:

$$
C_{e q}=C(2 n+1) \text {. }
$$

Each SCC cell can provide an additional gain in the output voltage. Thus, the output peak voltage for the complete structure can be defined by:

$$
V_{o p}=(n+1) M E \text {. }
$$

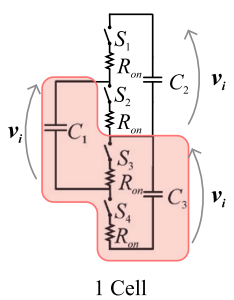

(a)

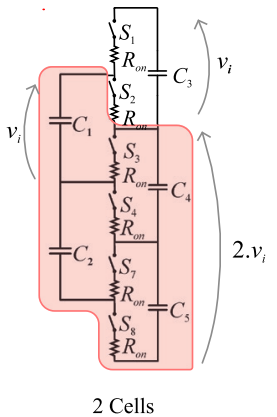

(b)

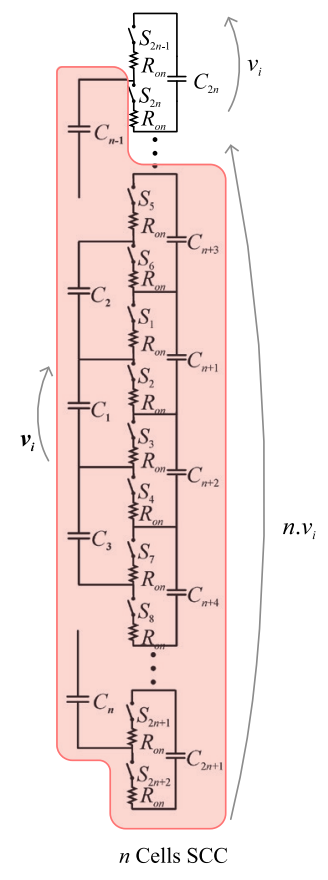

(c)

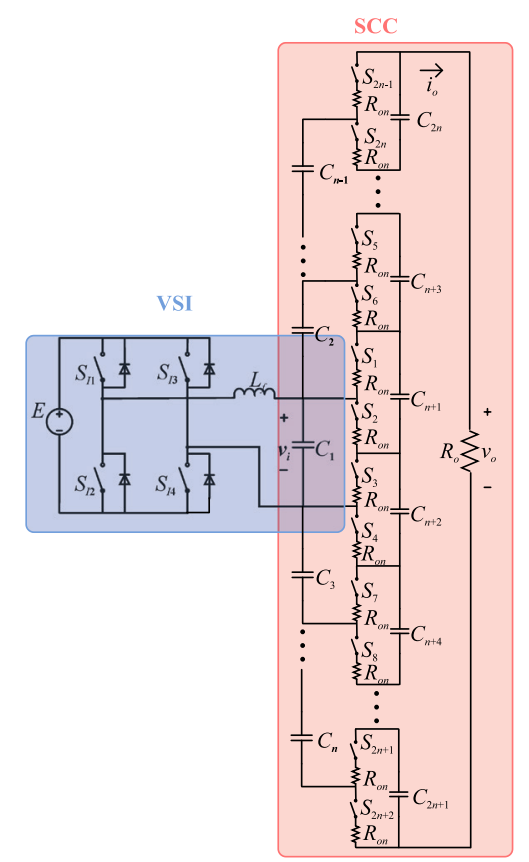

(d)
Fig. 10. Generalization for $n$ cells: (a) One-cell SCC; (b) Two-cells SCC; (c) $n$-cells SCC; (d) Generic structure of the VSI-SCC with $n$ SCC cells.

Finally, the transfer function of the proposed topology for the structure shown in Figure 10(c) is given by:

$$
G_{3}(s)=\frac{\hat{v}_{o}}{\hat{d}}=\frac{(n+1) E}{s^{2} L_{f} C_{e q}+s \frac{L_{f}}{R_{e q}}+1} .
$$

Similarly, the equivalent circuit for a structure with $n$ SCC cells is shown in Figure 11.

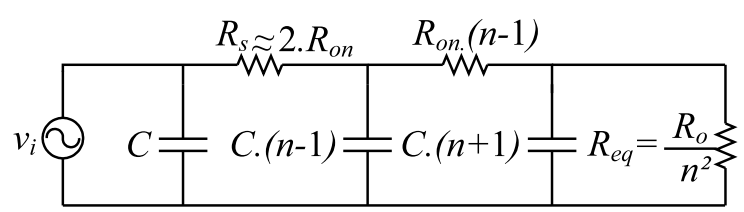

Fig. 11. Equivalent circuit for a structure with $n$ SCC cells.

\section{PROTOTYPE AND EXPERIMENTAL RESULTS}

The theoretical concepts developed in this paper was verified in a $1 \mathrm{kVA}$ prototype. They were built separately as two cells and subsequently connected to each other. The specifications for the two prototypes are shown in Table I, and the controller specifications are shown in Table II. The SCC topology was built using two series-connected MOSFETs with a common source. The capacitors are subject to high frequency and high value of currents and besides that to a high voltage stress. Therefore, an AC voltage is applied in these capacitors. Thus, is common to use polypropylene film capacitors. The main components used to build the SCC prototype are shown in Table III. The VSI was build with a integrated IGBT module. The main components of the VSI are shown in Table IV. The schematic and gate driver circuitry for the VSI+SCC structure are shown in Figures 12 (a), 12 (b) and 12 (c).

The capacitors, switches and switching frequency from SCC stage are defined to operate in PC mode, as was presented in in Figure 3. Hence, the current across the SCC switches at the worst case (at peak of $v_{i}$ voltage) was verified by simulation and the result is seen in Figure 13. The currents obtained are similar to PC theoretical curve shown in Figure 4, which corroborates the proposed design.

TABLE I VSI and SCC Specifications

\begin{tabular}{cccc}
\hline \multicolumn{1}{l}{ VSI } & \multicolumn{2}{c}{ SCC } \\
\hline$S$ & $1000 \mathrm{VA}$ & $S$ & $1000 \mathrm{VA}$ \\
$E$ & $200-300 \mathrm{~V}$ & $V_{\text {irms }}$ & $110 \mathrm{~V}$ \\
$V_{\text {irms }}$ & $110 \mathrm{~V}$ & $V_{\text {orms }}$ & $220 \mathrm{~V}$ \\
$f_{o}$ & $60 \mathrm{~Hz}$ & $f_{o}$ & $60 \mathrm{~Hz}$ \\
$f_{s}$ & $20 \mathrm{kHz}$ & $f_{s}$ & $100 \mathrm{kHz}$ \\
$\Delta_{\text {ILmax }}$ & $20 \%$ & $C_{1}, C_{2}, C_{3}$ & $20 \mu \mathrm{F}$ \\
$L_{f}$ & $700 \mu \mathrm{H}$ & & \\
$C_{e q}$ & $60 \mu \mathrm{F}$ & & \\
\hline
\end{tabular}

Figure 14(a) shows the voltage across the SCC switches, where the maximum value reached is close to the VSI output peak voltage. Figure 14(b) shows the output voltage $\left(v_{o}\right)$, the input voltage at $\mathrm{SCC}\left(v_{i}\right)$, the control (reference) voltage $\left(v_{c}\right)$ and dc input voltage $(E)$ at the VSI input terminal. In this figure it is clearly shown that $v_{o}$ is twice $v_{i}$, and therefore the VSI-SCC topology properly inverts and steps up the input voltage. This test was carried for the no-load case to test the 


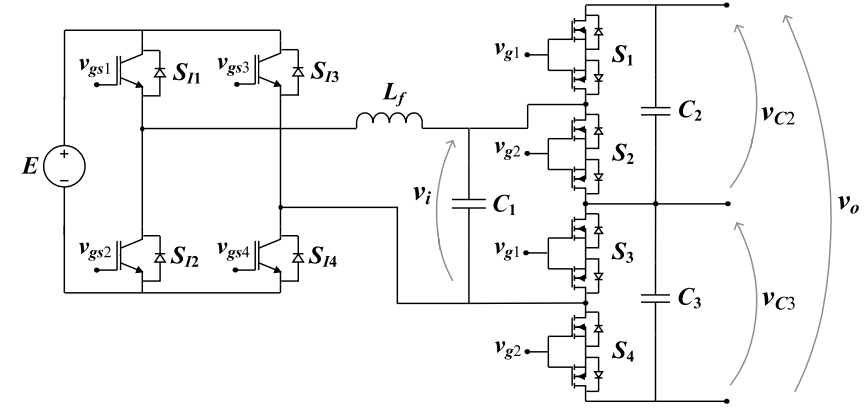

(a)

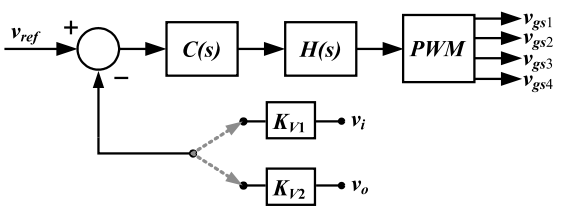

(b)

(c)

Fig. 12. (a) Schematic; (b) Gate driver circuitry for VSI stage; (c) Gate driver circuitry for SCC stage.

TABLE II

Control Specifications

\begin{tabular}{lc}
\hline Phase margin of the system & $90^{\circ}$ \\
Zero dB crossing over & $600 \mathrm{~Hz}$ \\
PI zero $(\omega z)$ & $533 \mathrm{rad} / \mathrm{s}$ \\
PI gain & 0.82 \\
Center frequency of the band-rejection filter & $796 \mathrm{~Hz}$ \\
Bandwidth of the band-rejection filter & $486 \mathrm{~Hz}$ \\
LC filter resonant frequency & $776 \mathrm{~Hz}$ \\
\hline
\end{tabular}

TABLE III

SCC Main Components

\begin{tabular}{lc}
\hline Description & Values \\
\hline MOSFET & FQA62N25C $\left(R_{\text {on }}=60 \mathrm{~m} \Omega\right)$ \\
Polypropylene Capacitors & $932 \mathrm{C} 4 \mathrm{~W} 10 \mathrm{~J}-\mathrm{F}$ \\
(two in parallel) & $(10 \mu \mathrm{F} / 400 \mathrm{~V} / \mathrm{ESR}=1.8 \mathrm{~m} \Omega)$ \\
MOSFET Driver & $\mathrm{UCC} 27424$ \\
Pulse Width Modulator & $\mathrm{UC} 3525$ \\
\hline
\end{tabular}

TABLE IV

VSI Main Components

\begin{tabular}{lc}
\hline Description & Values \\
\hline IGBT MODULE (Integral gate driver) & FNA41060 (660V-10A) \\
Control & Operational Amplifiers \\
Voltage transducer & LV 25-P \\
Inductor & $700 \mu \mathrm{F}-60 \mathrm{~Hz}$ \\
\hline
\end{tabular}

system stability.

The experimental results shown in Figure 14(c) and Figure 14(d) verified the converter controllability for a load step of $50 \%$ to $100 \%$ (see $i_{o}$ current). Two tests were carried out, one with a feedback control at the input terminal of the SCC topology and the other one at the output of the proposed topology. In both cases, the control was stable and controlled the system correctly. Furthermore, it had a fast dynamic response.

Voltage regulation at the converter output voltage was also

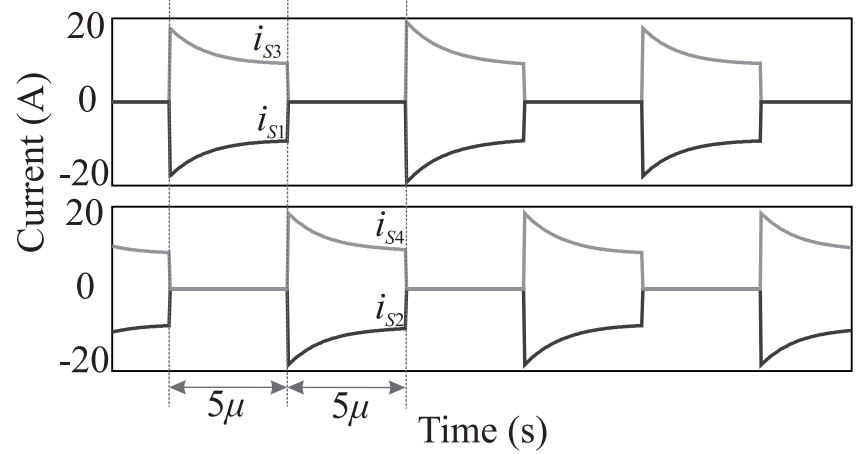

Fig. 13. Current across the SCC switches.

carried out for both control methods and the results are shown in Figure 15. From this figure, it is possible to conclude that on using feedback control at the output voltage $\left(v_{o}\right)$ the system obtains a better regulation voltage. This can be explained by the different approaches to the losses in the two control methods. When the feedback control is placed at $v_{i}$, the control does not consider the losses in the SCC structure. On the order hand, if the feedback control is carried out at the output voltage, the control will regulate the voltage considering the losses in both converters.

The experimental results obtained with a RL load are reported in Figure 16(a) and Figure 16(b), with a feedback control at the input $\left(v_{i}\right)$ and the output $\left(v_{o}\right)$ terminals of the SCC topology. The system shows stability using both methods, however, once again the regulation voltage provided better results when the feedback control was placed at the output voltage $\left(v_{o}\right)$.

The split-phase characteristic was also tested. To carry out these tests, a resistive-inductive load $(55 \Omega+45 \mathrm{mH})$ was placed at output $v_{C 2}$ and resistive loads $(60 \Omega$ and 120 $\Omega$ respectively) were added at outputs $v_{C 3}$ and $v_{o}$ (see Figure 12(a)). Even with different loads at each output the voltages remained regulated. The results are shown in Figure 16(c) and Figure 16(d).

Results for the SCC converter operating with $1 \mathrm{~kW}$ are given in [18] and [23], and the efficiency reached $96 \%$. Furthermore, during the test it was observed that the VSI converter reached an efficiency of $95 \%$. Therefore, the complete structure has an efficiency of approximately $91 \%$. The efficiency curves of the VSI, the SCC, and the VSI+SCC are shown in Figure 17.

\section{COMPARISON BETWEEN THE PROPOSED CONVERTER WITH CONVENTIONAL SOLUTIONS}

This paper proposes an integration between VSI and SCC topologies, which provides a higher voltage at the output compared with the input. For this reason, the proposed structure is compared with conventional step-up inverter solutions, as Z-Source Inverter (ZSI) [10], [32][35], Differential Boost Inverter (DBI) [5], [36], conventional two-stage Boost-Buck inverter (dc-dc Boost converter + classical VSI, named as TS-BBI) and classical Buck VSI + autotransformer (named as VSI+AT). This comparison is shown in Tables V and VI, considering a LC filter at the output, 


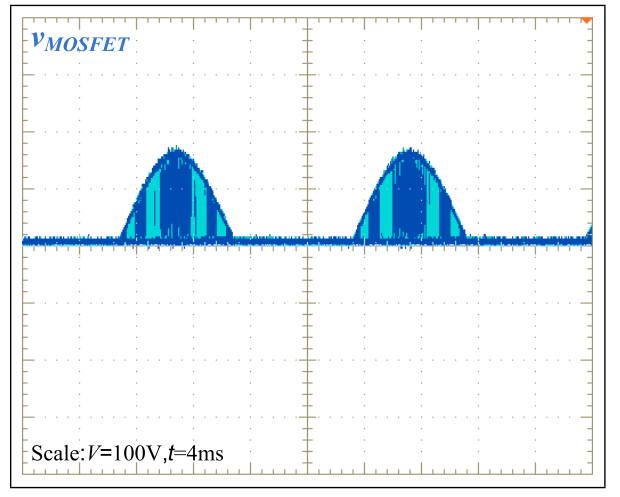

(a)

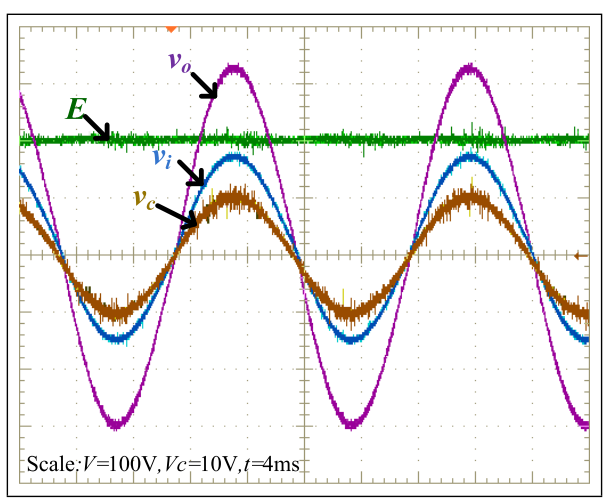

(b)

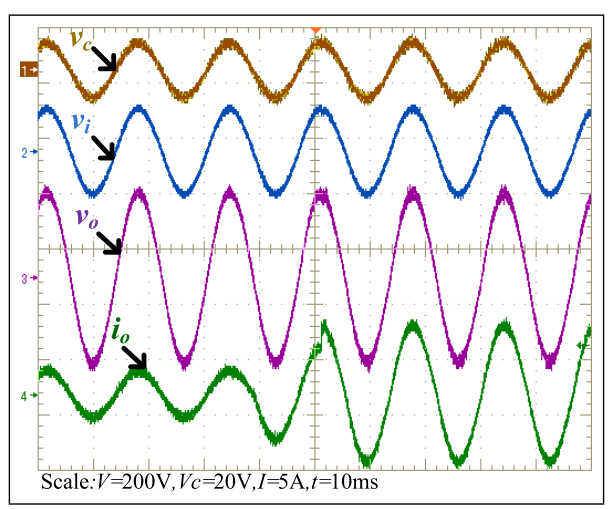

(c)

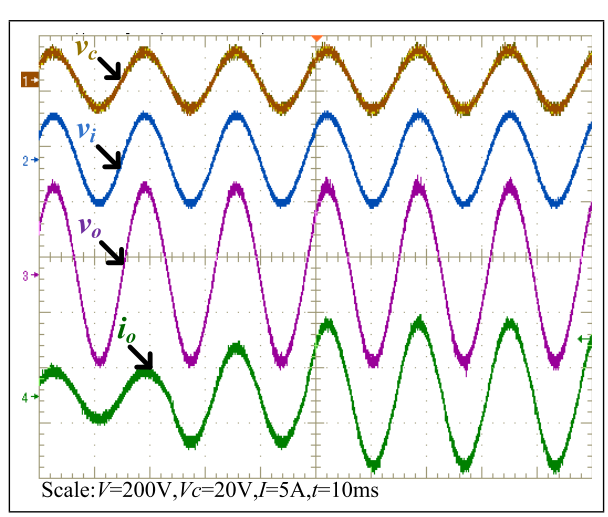

(d)

Fig. 14. Experimental results: (a) SCC switch voltage; (b) Output voltage $\left(v_{o}\right)$, voltage at the SCC input terminals $\left(v_{i}\right)$, control voltage $\left(v_{c}\right)$ and dc input voltage $(E)$ at the VSI input terminal for no-load case; (c) Load step response with feedback control at $v_{i}$; (d) Load step response with feedback control at $v_{o}$.

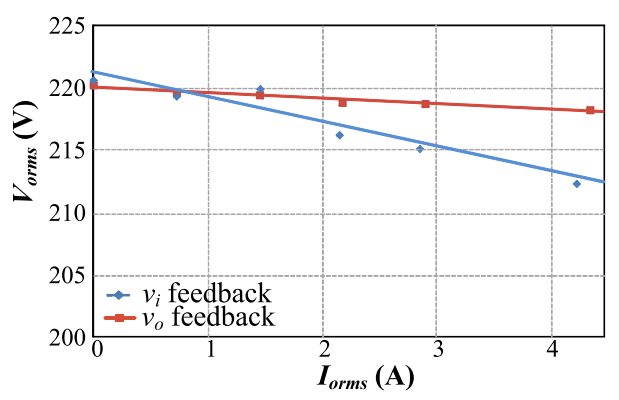

Fig. 15. Regulation voltage considering feedback control at the input $v_{i}$ and the output $v_{o}$ terminals of the SCC topology.

needed to ensure a sinusoidal output voltage in each topology.

TABLE V

Quantitative Comparison Between the Proposed Converter and Other Solutions

\begin{tabular}{lccccc}
\hline $\begin{array}{l}\text { Number of } \\
\text { elements }\end{array}$ & ZSI $^{1}$ & DBI $^{2}$ & TS-BBI $^{3}$ & VSI+AT $^{6}$ & VSI+SCC $^{4}$ \\
\hline Inductors $^{5}$ & 3 & 2 & 2 & 1 & 1 \\
Capacitors $^{5}$ & 3 & 3 & 2 & 1 & 3 \\
Autotransformer $^{6}$ & - & - & - & 1 & - \\
Diodes $_{\text {Active switches }}$ & 5 & 4 & 5 & 4 & 12 \\
Driver circuits & 4 & 4 & 5 & 4 & 12 \\
\hline
\end{tabular}

${ }^{1}$ Based on [10], [32]-[35]. ${ }^{2}$ Based on [5], [36]. ${ }^{3}$ Based on [34], [35]. ${ }^{4}$ Consider $n=1 .{ }^{5}$ Consider the LC output filter. ${ }^{6}$ Low frequency.

TABLE VI

Qualitative Comparison Between the Proposed Converter and Other Solutions

\begin{tabular}{lccccc}
\hline Characteristics & ZSI $^{1}$ & DBI $^{2}$ & $\begin{array}{c}\text { TS- } \\
\text { BBI }^{3,4}\end{array}$ & $\begin{array}{c}\text { VSI+ } \\
\mathbf{A T}^{4,5}\end{array}$ & $\begin{array}{c}\text { VSI+ } \\
\text { SCC }^{4,5}\end{array}$ \\
\hline Boost factor & $\frac{1}{1-2 \cdot d}$ & $\frac{1}{1-d}$ & $\frac{1}{1-d_{\text {boost }}}$ & $a$ & $n$ \\
Static Gain & $\frac{1}{1-2 \cdot d}$ & $\frac{2 \cdot d-1}{d \cdot(1-d)}$ & $\frac{d_{\text {buck }}}{1-d_{\text {boost }}}$ & $d_{\text {buck }} \cdot a$ & $d_{\text {buck }} \cdot n$ \\
$\begin{array}{l}\text { Voltage } \\
\text { stress factor }\end{array}$ & $\frac{1}{1-d}$ & $\frac{1}{1-d}$ & $\frac{1}{1-d_{\text {boost }}}$ & $E$ & $E$ \\
$\begin{array}{l}\text { Gain } \\
\begin{array}{l}\text { Characteristic } \\
\text { Complexity } \\
\text { of controller }\end{array}\end{array}$ & $\begin{array}{c}\text { Linear } \\
\text { High }\end{array}$ & $\begin{array}{c}\text { Non } \\
\text { Linear }\end{array}$ & $\begin{array}{c}\text { Non } \\
\text { Linear }\end{array}$ & Linear & Linear \\
\hline
\end{tabular}

${ }^{1}$ Based on [10], [32]-[35]. ${ }^{2}$ Based on [5], [36]. ${ }^{3}$ Based on [34], [35]. ${ }^{4}$ Two-stage topologies can be presented by two duty cycles, one for Boost stage $\left(d_{\text {Boost }}\right)$ and another for Buck stage $\left(d_{B u c k}\right) .{ }^{5}$ Variable $a$ is the autotransformer ratio and $n$ is the number of SC cells. ${ }^{6}$ In the worst case, the ZSI has other voltage stresses on Z-capacitor, which can be seen in references [32], [34], [35].

The quantitative analysis presented in Table $\mathrm{V}$ compares the VSI+SCC and other conventional solutions. The proposed converter employs a fewer number of magnetic components, however, it has higher number of switches, being a typical characteristic of switching capacitor converters.

A qualitative analysis is also presented in Table VI. The proposed converter has a linear boost factor, i.e., a linear static gain, which is similar to the VSI+AT solution. The others stepup structures have a non-linear boost factor (as shown in Table VI) and, consequently, a non-linear static gain. A linear boost factor characteristic facilitates the proposed converter control system, however, it should built with more SC cells to obtain higher gains. 


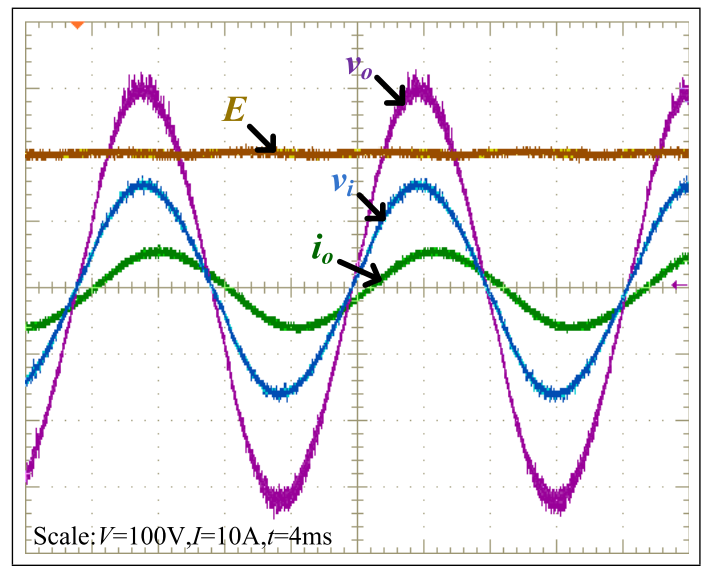

(a)

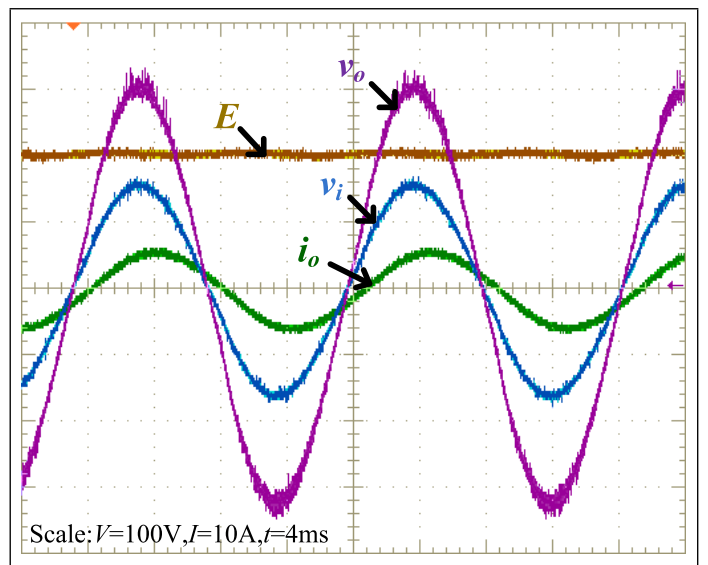

(b)

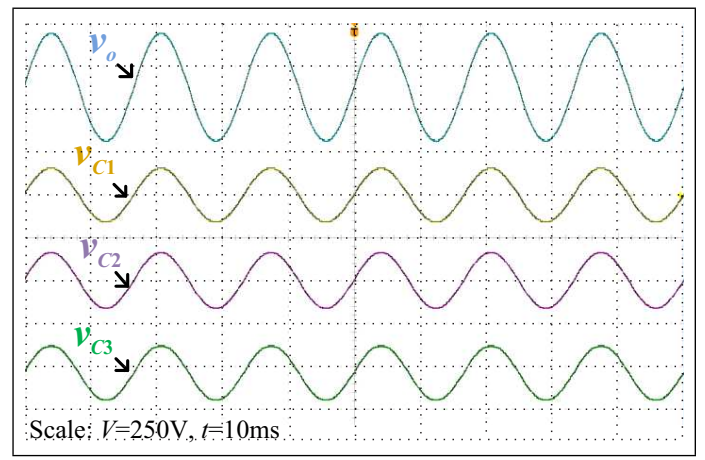

(c)

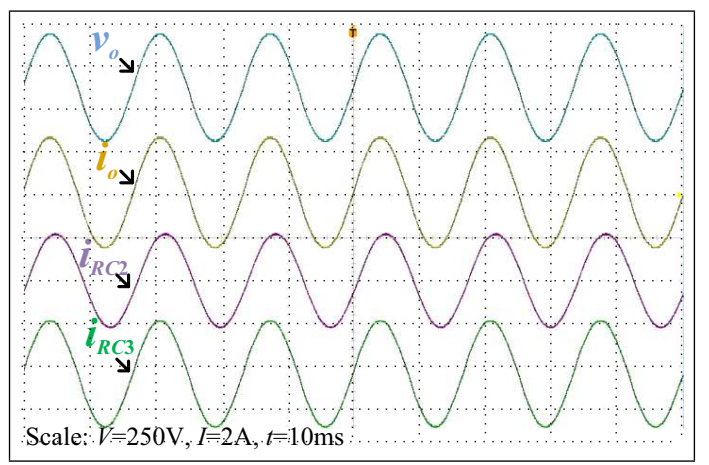

(d)

Fig. 16. Experimental results: (a) Under RL load, with feedback control at $v_{i}$; (b) Under RL load, with feedback control at $v_{o}$; (c) For the split-phase outputs: voltage waveforms; (d) For the split-phase outputs: current waveforms.

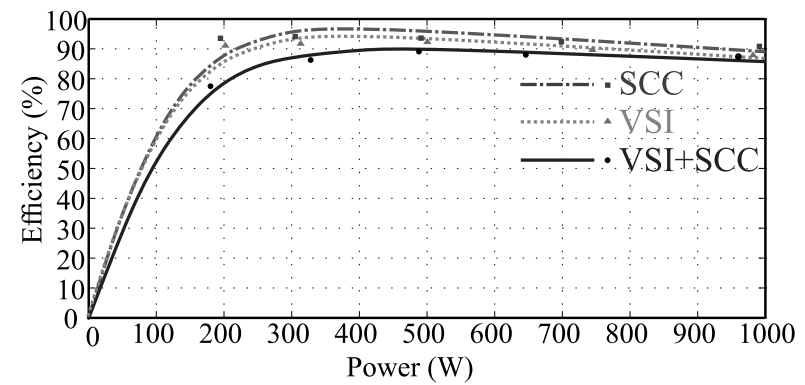

Fig. 17. Efficiency curves of the complete and individual structures.

Another important characteristic that should be analyzed is the voltage stress across the switches. The semiconductors of VSI+SCC and VSI+AT topologies have a maximum voltage equal to the input voltage, which is independent of the SC cells number. On the other hand, the maximum voltage across the semiconductors of Z-Source and Boost topologies are dependent of the operational point.

Therefore, because both SCC and autotransformer have linear boost factor characteristic, one can conclude that the proposed converter has some similarities with the VSI+AT solution, and, thus, the last topology is used to carry out a qualitative and a quantitative analysis. For this reason, a comparison between the SCC prototype and a commercial autotransformer was carried out and the results are shown in Table VII. The SCC has a lower power density than the autotransformer; however, it has much higher specific power. Therefore, if the two converters (VSI-SCC) are placed on the same board and the magnetic components are optimized, it is expected that the final volume of the proposed converter could achieve a higher power density value.

TABLE VII

\section{Comparison Between the SCC and an Autotransformer}

\begin{tabular}{lcc}
\hline & Autotransformer & SCC \\
\hline Volume $\left(\mathrm{cm}^{3}\right)$ & 1109.5 & 1449 \\
Mass $(\mathrm{kg})$ & 2.7 & 0.7 \\
Aparent Power (VA) & 1010 & 1000 \\
Power Density (VA/cm $\left.{ }^{3}\right)$ & 0.91 & 0.69 \\
Specific Power $(\mathrm{VA} / \mathrm{kg})$ & 374.1 & 1428.6 \\
\hline
\end{tabular}

\section{CONCLUSIONS}

The goal of the study reported herein was to investigate the possibility for integration between the VSI and the SCC converters. It results in a transformerless step-up inverter where the static gain can be increased using more switchedcapacitor cells in series. Furthermore, the proposed converter also presents split-phase characteristics at the output stage, which can expand the range of potential applications for the proposed converter. The proposed structure (VSI-SCC) is designed as a transformerless step-up inverter.

Static and dynamic characteristics were analyzed for both the VSI and SCC topologies individually and then the two converters were attached to each other to validate the proposed converter. To create the VSI and the SCC models, equivalents circuits were proposed and tested using numerical simulations and satisfactory results were obtained. The analysis was expanded to $n$ SCC cells.

Once the models for the two converters had been obtained, 
controllers were designed considering feedback control at two locations: at the SCC input terminal $\left(v_{i}\right)$ and at the SCC output terminal $\left(v_{o}\right)$. Therefore, to determine the best feedback control technique the converter regulation voltage at the output terminal was measured and the feedback control placed at $v_{o}$ presented better results.

The theoretical concepts presented in this paper were validated through experimental results for both resistive and inductive loads, in both cases showing promising results in applications which require step-up inverters and split-phase outputs. The fact that the converter proposed in this paper does not use low-frequency, bulky and heavy transformers makes it competitive in terms of volume, weight and efficiency when compared to conventional structures.

The proposed converter has higher specific power and lower power density when compared with commercial autotransformers.

\section{REFERENCES}

[1] D. Boroyevich, I. Cvetkovic, D. Dong, R. Burgos, F. Wang, F. Lee, "Future electronic power distribution systems a contemplative view", in 12th International Conference on Optimization of Electrical and Electronic Equipment (OPTIM), pp. 1369-1380, 2010.

[2] J. D. van Wyk, F. C. Lee, "On a Future for Power Electronics", IEEE Journal of Emerging and Selected Topics in Power Electronics, vol. 1, no. 2, pp. 59-72, June 2013.

[3] J. D. van Wyk, F. C. Lee, D. Boroyevich, Z. Liang, $\mathrm{K}$. Yao, "A future approach to integration in power electronics systems", in 29th Annual Conference of the IEEE Industrial Electronics Society, vol. 1, pp. 10081019, 2003.

[4] M. Islam, S. Mekhilef, "H6-type transformerless single-phase inverter for grid-tied photovoltaic system", IET Power Electronics, vol. 8, no. 4, pp. 636-644, Apr 2015.

[5] R. O. Caceres, I. Barbi, "A boost DC-AC converter: analysis, design, and experimentation", IEEE Transactions on Power Electronics, vol. 14, no. 1, pp. 134-141, Jan 1999.

[6] A. Ravindranath, S. K. Mishra, A. Joshi, "Analysis and PWM Control of Switched Boost Inverter", IEEE Transactions on Industrial Electronics, vol. 60, no. 12, pp. 5593-5602, Dec 2013.

[7] M. Jang, M. Ciobotaru, V. G. Agelidis, "A SinglePhase Grid-Connected Fuel Cell System Based on a Boost-Inverter", IEEE Transactions on Power Electronics, vol. 28, no. 1, pp. 279-288, Jan 2013.

[8] C. J. Gajanayake, F. L. Luo, H. B. Gooi, P. L. So, L. K. Siow, "Extended-Boost Z-Source Inverters", IEEE Transactions on Power Electronics, vol. 25, no. 10, pp. 2642-2652, Oct 2010.

[9] P. C. Loh, S. W. Lim, F. Gao, F. Blaabjerg, "Three-Level Z-Source Inverters Using a Single LC Impedance Network", IEEE Transactions on Power Electronics, vol. 22, no. 2, pp. 706-711, March 2007.
[10] M. K. Nguyen, Y. C. Lim, S. J. Park, "A Comparison Between Single-Phase Quasi-Z-Source and QuasiSwitched Boost Inverters", IEEE Transactions on Industrial Electronics, vol. 62, no. 10, pp. 6336-6344, Oct 2015.

[11] B. Poorali, A. Torkan, E. Adib, "High step-up Z-source DC-DC converter with coupled inductors and switched capacitor cell”, IET Power Electronics, vol. 8, no. 8, pp. 1394-1402, July 2015.

[12] G. L. Piazza, I. Barbi, "New Step-Up/Step-Down DC-AC Converter", IEEE Transactions on Power Electronics, vol. 29, no. 9, pp. 4512-4520, Sept 2014.

[13] Y. Jiao, F. L. Luo, "N-switched-capacitor buck converter: topologies and analysis", IET Power Electronics, vol. 4, no. 3, pp. 332-341, March 2011.

[14] J. A. Reyes-Malanche, N. Vázquez, J. Leyva-Ramos, "Switched-capacitor quadratic buck converter for wider conversion ratios", IET Power Electronics, vol. 8, no. 12, pp. 2370-2376, Dec 2015.

[15] C. K. Chan, K. W. E. Cheng, S. L. Ho, "Half-bridge converter based on switched-capacitor resonance without using deadtime control for automotive applications", IET Power Electronics, vol. 4, no. 6, pp. 657-662, July 2011.

[16] H. Choi, M. Jang, V. G. Agelidis, "Zero-currentswitching bidirectional interleaved switchedcapacitor DC-DC converter: analysis, design and implementation", IET Power Electronics, vol. 9, no. 5, pp. 1074-1082, Apr 2016.

[17] D. F. Cortez, I. Barbi, "A Family of High-Voltage Gain Single-Phase Hybrid Switched-Capacitor PFC Rectifiers", IEEE Transactions on Power Electronics, vol. 30, no. 8, pp. 4189-4198, Aug 2015.

[18] N. C. D. Pont, M. D. Vecchia, G. Waltrich, T. B. Lazzarin, "Step-up inverter conceived by the integration between a Full-Bridge inverter and a Switched Capacitor Converter", in 2015 IEEE 13th Brazilian Power Electronics Conference and 1st Southern Power Electronics Conference (COBEP/SPEC), pp. 1-6, 2015.

[19] Y. Ye, K. W. E. Cheng, "Single-switch single-inductor multi-output pulse width modulation converters based on optimised switched-capacitor", IET Power Electronics, vol. 8, no. 11, pp. 2168-2175, Nov 2015.

[20] O. Y. Wong, H. Wong, W. S. Tam, C. W. Kok, "Parasitic capacitance effect on the performance of two-phase switched-capacitor DC-DC converters", IET Power Electronics, vol. 8, no. 7, pp. 1195-1208, July 2015.

[21] J. C. Rosas-Caro, J. C. Mayo-Maldonado, F. MancillaDavid, A. Valderrabano-Gonzalez, F. B. Carbajal, "Single-inductor resonant switched capacitor voltage multiplier with safe commutation", IET Power Electronics, vol. 8, no. 4, pp. 507-516, Apr 2015.

[22] A. Kushnerov, S. Ben-yaakov, "Unified algebraic synthesis of generalised Fibonacci switched capacitor converters", IET Power Electronics, vol. 7, no. 3, pp. 540-544, March 2014. 
[23] T. B. Lazzarin, M. P. Moccelini, I. Barbi, "Splitphase switched-capacitor ac-ac converter", IET Power Electronics, vol. 8, no. 6, pp. 918-928, June 2015.

[24] T. B. Lazzarin, M. D. Vecchia, I. Barbi, "Experimental validation of a proposal for a $3.5 \mathrm{kVA}$ three-phase magnetic-less solid-state autotransformer (SSAT) based on the switched-capacitor principle", in 2015 IEEE International Conference on Industrial Technology (ICIT), pp. 993-998, 2015.

[25] R. de Souza Santos, T. B. Lazzarin, I. Barbi, "A new half-bridge Hybrid Switched-Capacitor inverter", in 2015 IEEE 13th Brazilian Power Electronics Conference and 1st Southern Power Electronics Conference (COBEP/SPEC), pp. 1-6, 2015.

[26] Y. Hinago, H. Koizumi, "A Switched-Capacitor Inverter Using Series/Parallel Conversion With Inductive Load", IEEE Transactions on Industrial Electronics, vol. 59, no. 2, pp. 878-887, Feb 2012.

[27] A. Tsunoda, Y. Hinago, H. Koizumi, "A grid connected inverter with switched capacitor inverter using series/parallel conversion", in Power Electronics and Motion Control Conference (EPE/PEMC), pp. LS7c.4-1-LS7c.4-5, 2012.

[28] S. Ben-Yaakov, "Behavioral Average Modeling and Equivalent Circuit Simulation of Switched Capacitors Converters", IEEE Transactions on Power Electronics, vol. 27, no. 2, pp. 632-636, Feb 2012.

[29] M. D. Vecchia, T. B. Lazzarin, I. Barbi, "Estudo de Conversores Esáticos CA-CA Monofásicos e Trifásicos Baseados no Princípio do Capacitor Chaveado", Eletrônica de Potência - SOBRAEP, vol. 20, no. 2, pp. 161-171, May 2015.

[30] R. F. Coelho, R. Schweitzer, D. C. Martins, "Obtenção de modelo médio para grandes sinais voltados a simulação de conversores estáticos", in Congresso Brasileiro de Automática, pp. 4361-4368, Sept 2012.

[31] R. Erickson, D. Maksimovic, Fundamentals of Power Electronics, Power electronics, Springer US, 2001.

[32] M. Zhu, K. Yu, F. L. Luo, "Switched Inductor Z-Source Inverter", IEEE Transactions on Power Electronics, vol. 25, no. 8, pp. 2150-2158, Aug 2010.

[33] E. Babaei, E. S. Asl, M. H. Babayi, S. Laali, "Developed embedded switched-Z-source inverter", IET Power Electronics, vol. 9, no. 9, pp. 1828-1841, July 2016.

[34] B. Farhangi, S. Farhangi, "Comparison of z-source and boost-buck inverter topologies as a single phase transformer-less photovoltaic grid-connected power conditioner", in Power Electronics Specialists Conference, pp. 1-6, 2006.

[35] J. Li, J. Liu, Z. Liu, "Comparison of Z-source inverter and traditional two-stage boost-buck inverter in grid-tied renewable energy generation", in Power Electronics and Motion Control Conference, pp. 14931497, 2009.

[36] P. Sanchis, A. Ursaea, E. Gubia, L. Marroyo, "Boost DC-AC inverter: a new control strategy", IEEE Transactions on Power Electronics, vol. 20, no. 2, pp. 343-353, March 2005.

\section{BIOGRAPHIES}

Neilor Colombo Dal Pont was born in Criciúma, Santa Catarina State, Brazil, in 1989. He received the B.Sc. degree in Electrical Engineering from the Federal University of Santa Catarina (UFSC), Florianópolis, Brazil, in 2015.nHe is currently doing master's degree at the Department of Electrical and Electronic Engineering (EEL) from the UFSC, at the Power Electronics Institute (INEP). His interests include switched-capacitor converters, inverters, high-voltage dc-dc converters and grid connected systems.

Gierri Waltrich was born in Joaçaba, Brazil, in 1979. He received the B.S. and M.S. degrees in electrical engineering from the Federal University of Santa Catarina, Florianópolis, Brazil, in 2007 and 2009, respectively, and the Ph.D. degree from Eindhoven University of Technology, Eindhoven, The Netherlands, in 2013, all in electrical engineering. He is currently an Assistant Professor with the Federal University of Santa Catarina, Joinville, Brazil.

Telles Brunelli Lazzarin was born in Criciúma, Santa Catarina State, Brazil, in 1979. He received the B.Sc., M.Sc. and Ph.D. degrees in Electrical Engineering from the Federal University of Santa Catarina (UFSC), Florianópolis, Brazil, in 2004, 2006 and 2010, respectively.He is currently an Adjunct Professor at the Department of Electrical and Electronic Engineering (EEL) from the UFSC, and he also works as a Researcher at the Power Electronics Institute (INEP), UFSC. His interests include switched-capacitor converters, inverters, rectifiers, parallel operation of converters, high-voltage dc-dc converters and conversion systems for small wind turbines. Dr Lazzarin is a member of the Brazilian Power Electronic Society (SOBRAEP), IEEE Power Electronics Society (PELS) and IEEE Industrial Electronics Society (IES). 